\section{Call for openness about farm-animal experiments}

SIR - The recent call by the Nuffield Council on Bioethics ("UK panel urges animal researchers to go public" Nature 435, 392; 2005) for scientists to discuss more openly the use of animals in experiments should start with farm animals. During their lives, most commercial livestock are subject to experimentation at several levels: the individual farm; the national flock or herd; and the global livestock industry. Indeed, at a more basic level, a farm's day-to-day and year-to-year refinement of animalmanagement practices and business activities is itself scientific, experimental and involves animals.

\section{"Commercial livestock are subject} to experimentation at several levels: the farm, the national flock or herd and the global livestock industry." - lan G. Colditz

At the individual farm level, genetic improvement programmes provide one example of animal experimentation through collection of data on pedigree and on individual performance such as body weight and milk production. Another example is collection of blood for serology, on the farm or at the point of slaughter, to test hypotheses on disease epidemiology.

What benefits might flow from a broader appreciation of commercial farms' dependence on farm-based animal experimentation within their enterprise and more broadly across their industry?

First, experimental practices, especially genetic improvement programmes, can have welfare consequences that deserve our attention (see W. M. Rauw et al. Livest. Prod. Sci. 56, 15-33; 1998). These can be beneficial, for example when animals are selected for calving ease. They can also be harmful, for example in broiler chickens whose legs are weakened by selection for fast growth rate.

Second, the discussion may help illuminate the nature of human-animal relationships and potentially reduce the stigma associated with use of animals in universities and research institutes.

Ian G. Colditz

CSIRO Livestock Industries, Locked Bag 1, PO,

Armidale, New South Wales 2350, Australia

\section{Plagiarism criteria ignore the way research evolves}

SIR - Your Special Report on plagiarism, "Taking on the cheats" (Nature 435, 258-259; 2005), does not, in my opinion, appreciate the way in which scientific research evolves.

In my experience, incremental progress is often reported at one or more scientific conferences, until a comprehensive manuscript can be submitted to a reputable journal for publication. The work may be further published in research monographs, in review articles and, on occasion, in textbooks.

It seems to me a misunderstanding to insist that a piece of work must be published only once.

A series of progress reports would naturally have extended sections in common - if this were not allowed, no scientist would consider presenting work at a conference with published proceedings. Increasingly, conference papers are being published as regular books and sometimes even as special issues of standard journals. Is it not defeating the scientific purpose of conferences if final papers are expected, rather than discussion papers on work in progress?

Similar conflicts can arise between journal and book publishers. I submitted a paper to a scientific journal and later incorporated a description of it in a research monograph. However, the efficient book publisher got the monograph on the street two months after receiving the manuscript, whereas the journal turned out to have a backlog resulting in accepted papers waiting more than a year to appear in print. In this instance, could I be accused of committing 'self-plagiarism' on the basis of overlaps, when I have no control over the schedules of the publishers?

Bent Sørensen

Department of Mathematics and Physics, Roskilde University, Universitetsvej 1, bld. 27, DK-4000 Roskilde, Denmark

\section{Six-word rule could turn description into plagiarism}

SIR - Your Special Report on the software that journal editors are considering to help them catch academic cheats (Nature 435, $258-259$; 2005) suggests that six words used contiguously in more than one published paper now constitutes plagiarism. I design novel oligonucleotides to inhibit STAT3 activity in hormone refractory prostate cancer. I use this phrase of more than six words to describe what I do in the introduction to my manuscripts. Am I commiting self-plagiarism?

Plagiarism must absolutely be defined not by words used but by data shown. That is the serious offence, not that someone reuses a key descriptive phrase in several papers. Beverly E. Barton Department of Surgery/Division of Urology, UMDNJ-NJMS MSB G519,

185 South Orange Avenue, Newark, New Jersey 07103, USA

\section{Penalties plus high-quality review to fight plagiarism}

SIR - Your Special Report (Nature 435, $258-259$; 2005) on plagiarism in scientific texts overlooks an important related problem, namely multiple publications of the same data (graphs or pictures).

The computer programs for identifying duplicate text in manuscripts do not seem capable of handling this particular kind of dishonesty. In one case I have identified, the authors had published the same electron micrographs repeatedly in different journals, and attempted to do so with a manuscript that was sent to me for review. In trying to hide self-plagiarism, the copied figures were presented upside down, rotated by $90^{\circ}$, or slightly cut or expanded. This is reminiscent of Jan Hendrik Schön's scientific misconduct (Nature 417, 367-368; 2002).

When I informed the editor, she rejected the paper with a letter stating that it was unacceptable, as a reviewer had detected the plagiarism. But there are good arguments for journals to go further and take punitive measures, such as notifying the authors' institution and, if applicable, their funding agency. Papers identified as fraudulent after publication should be removed from the web version of the journal and be replaced by a note disclosing the scientific misconduct. The authors' consent should not be required.

Even more serious sanctions may need to be discussed publicly and included in the guidelines for manuscript submission. For example, the authors could be banned from publishing, permanently or temporarily, at least in the cheated journal. Funding agencies could add pressure by stating that scientists practising scientific misconduct will be denied the right to submit proposals.

Last, but not least, many cases of scientific misconduct could be avoided if the work of good reviewers were appreciated more explicitly. I tell myself that I'm doing it for the benefit of science. But, lacking appreciation, some reviewers might do their job in a sloppy manner. Why not encourage them? The only journal I know that makes an award for excellence of review is Environmental Science and Technology. Publishing a list of the top 10 or 20 reviewers each year may encourage more in-depth evaluations of manuscripts. Klaus Wittmaack Institute of Radiation Protection, GSF National Research Centre for Environment and Health, 85758 Neuherberg Germary

Nature's policy on duplicate publications is outlined at www.nature.com/nature/ authors/policy/index.html\#a4. Nature has on occasion notifiedemployers concerning misconduct detected during peer review, and reserves the right to bring it to readers' attention - Editor, Nature. 